\title{
Analysis of the Traditional Lecture Method combined with the Seminar Teaching Method in the Graduate Education
}

\author{
WANG Xing-ju ${ }^{1,2}$, ZHAO Lin ${ }^{1}$ and GAO Gui-feng ${ }^{1}$ \\ 1 School of traffic and transportation, Shijiazhuang Tiedao University, Shijiazhuang, Hebei 050043, \\ China \\ 2 Traffic Safety and Control Laboratory of Hebei Province, Shijiazhuang, Heibei 050043, China
}

\begin{abstract}
The traditional teaching method gives full play to the teacher's leading role and enables the student to obtain more knowledge. But the traditional teaching method makes the students lose the learning initiative and creativity. Seminar teaching method is a kind of research type teaching method. It fully mobilizes students' learning initiative and creativity. The combination of the traditional lecture method and seminar emphasizes the teacher's leading role and play the students' initiative. Case study shows that the combination of the traditional lecture method and seminar is better than others. It is greatly significant for the cultivation of graduate students.
\end{abstract}

Keywords: Lecture method; Seminar; linear weighted; Graduate education; Education reform

\section{Introduction}

The traditional lecture method is the method that the teachers impart knowledge to students through oral language ${ }^{[1]}$. Lecture method includes telling method, interpretation method, speak pronunciation and speech method. Teachers use all kinds of teaching methods in teaching mostly accompanied with teaching method. This is the current education most commonly use a kind of teaching method in China. At present Chinese graduate education mode has had the very big change than before, but occupied mainstream is still "inheritance knowledge - accept knowledge" of the traditional model, that is, the teacher as the center, the classroom as the center, books as the center of the traditional teaching method ${ }^{[2-3]}$. Traditional teaching method is beneficial to give full play to the teacher's leading role and enable the students to obtain more knowledge. But teaching method make the students lose the learning initiative and creativity at the same time ${ }^{[4]}$.

Seminar teaching method is a kind of deliberative teaching method. Seminar can be translated into discussion, assembly. It is popular in Europe and the United States in the university classroom. It is a kind of teaching or academic communication. It is a kind of interactive teaching path that student discuss with teachers and experts for the study of a certain problem. Its core is to dig deeply course participants (students and teachers two aspects) academic potential, utmost ground a multi-angle and multi-level understanding interaction. Seminar teaching method makes students deepened the understanding of a subject and realized the academic exchange the best effect. Students can discuss some issues of common concern with teachers in a democratic and harmonious atmosphere ${ }^{[5-6]}$.

The traditional teaching method and seminar combination emphasizes the teacher's leading role. Teachers can deliver information from easy to difficult sequence. It will help students accept more knowledge and improve the efficiency of classroom teaching. It fully mobilizes the students' learning initiative and cultivates the students' ability of self-study. It benefits to train the students' oral communication ability and improve their participation ${ }^{[7]}$. This method is greatly significant for the cultivation of graduate students. 


\section{Methods}

The multiple comprehensive evaluation indexes look as a whole through the establishment of comprehensive evaluation of the teaching mode. The whole is a basic evaluation. According to the linear weighted synthesis ${ }^{[8]}$, we assume that, there is parameter $X_{1}, X_{2}, X_{3} \ldots X_{\mathrm{n}}$. Their corresponding weighting coefficient is $P_{1}, P_{2} \ldots$ $P_{n}$. Its computation formula is as follows.

$$
S=\sum_{i=1}^{n} X_{i} \times P_{i}
$$

- The teaching evaluation model is based on students' three evaluation indicator.

- Classroom performance $\mathrm{C}$ : the result is divided into good (9 points), good (eight points), pass (7 points), bad (5 points). Their weight is $0.4,0.3,0.2$, 0.1 , respectively.

- The final exam T: the result is divided into A (9 points) and $\mathrm{B}$ (8 points), C (7 points), D (6 points). Their weight is $0.45,0.3,0.15,0.1$, respectively.

- The number of paper $\mathrm{N}$ : published papers are divided into two types. One kind is included by SCI. The other one is included by EI. Their weight is $0.6,0.4$, respectively.

Their weighting is $0.2,0.3,0.5$ in the three types of evaluation index, respectively.

First of all, we are going to select some students. They have similar level. We divided the students into three groups. There is the same number of students in every group. They are used to three different teaching modes, respectively. The three teach modes are the traditional teaching method, seminar method, and traditional lecture method combined with the seminar method. Then, the proportion of the total score in some teaching methods of three kinds of evaluation multiplied by the weight of their accounts. Finally, we can draw a conclusion through the points of each method. Specific computation formula is as follows:

$$
\begin{aligned}
& S=P_{1} \times \frac{\sum_{i=1}^{n} C_{x_{i}\left(\mathrm{y}_{\mathrm{i}}, \mathrm{z}_{\mathrm{i}}\right)} \times P_{i}}{Q} \\
& +P_{2} \times \frac{\sum_{i=1}^{n} T_{x_{i}\left(\mathrm{y}_{\mathrm{i}}, \mathrm{z}_{\mathrm{i}}\right)} \times P_{i}}{Q}
\end{aligned}
$$

$+P_{3} \times \frac{\sum_{i=1}^{n} N_{x_{i}\left(\mathrm{y}_{\mathrm{i}}, \mathrm{z}_{\mathrm{i}}\right)} \times P_{i}}{Q}$

$$
\begin{aligned}
& Q=\sum_{i=1}^{n} C_{x_{i}\left(\mathrm{y}_{\mathrm{i}}, \mathrm{z}_{\mathrm{i}}\right)} \times P_{i} \\
& +\sum_{i=1}^{n} T_{x_{i}\left(\mathrm{y}_{\mathrm{i}}, \mathrm{z}_{\mathrm{i}}\right)} \times P_{i} \\
& +\sum_{i=1}^{n} N_{x_{i}\left(\mathrm{y}_{\mathrm{i}}, \mathrm{z}_{\mathrm{i}}\right)} \times P_{i}
\end{aligned}
$$

$C_{x_{i}\left(\mathrm{y}_{\mathrm{i}}, \mathrm{z}_{\mathrm{i}}\right)}$ - the students' classroom performance in teaching patterns $X$ or $Y$ or Z. $P_{i}$ is their respective weight.

$T_{x_{i}\left(\mathrm{y}_{\mathrm{i}}, \mathrm{z}_{\mathrm{i}}\right)}$-the students' final exam in teaching patterns $X$ or $Y$ or $Z . P_{i}$ is their respective weight.

$N_{x_{i}\left(\mathrm{y}_{\mathrm{i}}, \mathrm{z}_{\mathrm{i}}\right)}$-the number of papers that students published in teaching patterns $X$ or $Y$ or Z. $P_{i}$ is their respective weight.

Here we assume that, $S_{1}$ is evaluation in the traditional lecture method. $S_{2}$ is evaluation in seminar method. $S_{3}$ is evaluation in traditional lecture method combined with the seminar method.

We compare $S_{1}, S_{2}$ and $S_{3}$. The maximum one shows that its method is best method in the three methods. 


\section{Case study}

We select 30 students who have similar results and similar ability, then they divide into three groups in average. They are trained respectively by means of the above three kinds of teaching methods. A year later, their results are as follows in the three tables.

Table 1. Students' results in Traditional lecture method.

\begin{tabular}{ccccc}
\hline NAME & C & T & SCI & EI \\
\hline Zhang & Good & B & 1 & 1 \\
Yang & Good & B & 1 & 2 \\
Wang & Excellent & A & 3 & 4 \\
Song & Pass & B & 1 & 2 \\
Gao & Bad & C & 0 & 1 \\
Hao & Good & B & 2 & 1 \\
Liu & Pass & C & 1 & 2 \\
Hu & Pass & D & 1 & 1 \\
Zhang & Good & B & 2 & 1 \\
Wen & Good & B & 3 & 2 \\
\hline
\end{tabular}

Table 2. Students' results in seminar method.

\begin{tabular}{ccccc}
\hline NAME & C & T & SCI & EI \\
\hline Li & Excellent & A & 3 & 2 \\
Wang & Pass & B & 1 & 1 \\
Su & Good & B & 1. & 2 \\
Suo & Good & B & 2 & 3 \\
Chen & Bad & C & 1 & 1 \\
Yu & Good & B & 2 & 2 \\
Wang & Excellent & A & 4 & 3 \\
Yang & Pass & D & 1 & 1 \\
Zhang & Good & B & 2 & 3 \\
Jiang & Good & B & 1 & 2 \\
\hline
\end{tabular}

Table 3. Students' results in lecture method and seminar bonding method.

\begin{tabular}{ccccc}
\hline NAME & C & T & SCI & EI \\
\hline Zhang & Excellent & A & 4 & 5 \\
Suo & Good & A & 2 & 2 \\
Dai & Excellent & B & 3 & 2 \\
Feng & Excellent & A & 4 & 3 \\
Wang & Good & B & 2 & 4 \\
Nan & Good & B & 3 & 3 \\
Wang & Good & B & 3 & 2 \\
Niu & Excellent & A & 5 & 4 \\
Zhang & Excellent & A & 3 & 2 \\
Wang & Good & A & 3 & 2 \\
\hline
\end{tabular}

Through calculation, we can get $S_{1}=0.315$,

$S_{2}=0.323, \quad S_{3}=0.333$.

Because of $S_{3}>S_{2}>S_{1}$, we can draw the conclusion that the lecture method and seminar bonding is better than the traditional lecture method and the single seminar method.

In order to more clearly, directly display effect of three teaching methods, we will compare the students' average scores in the three teaching mode. We can see that the students do very well in the lecture method and seminar bonding from Figure 1. Its all kinds of index are better than the students' in the other two kinds of teaching method.

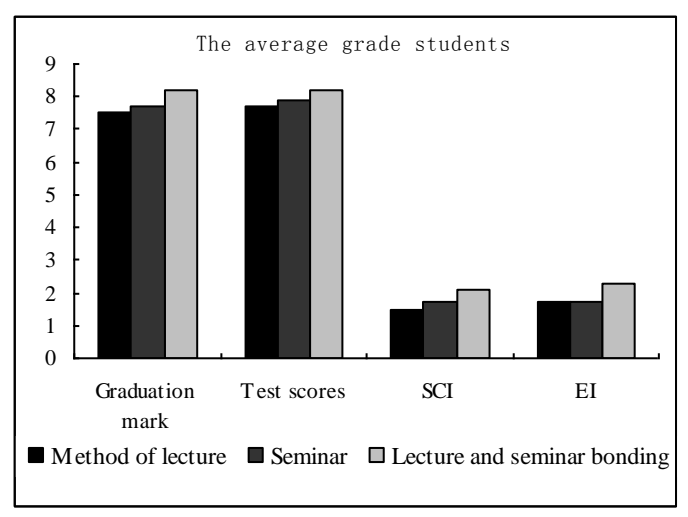

Figure. 1: the students' average result in three teaching methods. 


\section{Conclusion}

Through the investigation and analysis and case study, we can draw the conclusion that traditional the lecture method and seminar bonding is beneficial to improve the classroom efficiency and cultivate students' learning initiative and creativity. The teaching model should be introduced into China. It is greatly significant for the graduate student education.

\section{Acknowledgments}

This research is founded by the Social Scientific and Education Research Foundation, Education Department of Hebei Province of China (Grant No: GH122053). Moreover, this research is also the project supported by the Education Research Foundation, Shijiazhuang Tiedao university of China (Grant No: 110433).

\section{References}

[1] Yang Li-niang, Deng Jun, "Seminar: Training graduate students scientific research ability of the effective way", China's geological education, vol.3, pp. 5-7, 2005.

[2] Chen Tan, Cheng Ying, "Teaching, case teaching method and the teaching model is built", Hunan normal university education science journal, vol.3, pp. 57-59, 2004.

[3] Shen Wen-jie, Zhu Qiang, "Seminar Mode for Postgraduates", Academic Degrees \& Graduate Education, vol.7, pp. 3-4, 2002.

[4] Lin Feng-pei, "Seminar teaching model based on the theory of social interaction effects on the quality of post-graduate education", Journal of Chengdu College of Education, vol.4, no.20, pp. 45-47, 2006.

[5] Cong Li-xin, "Teaching method of reasonable and legitimate". Education research, vol.7, pp. 64-72, 2008.

[6] Chen Zhen-hua, "Teaching method and the crisis", Education theory and practice, vol.31, pp. 50-53, 2011.

[7] Zhao Dong-chen, "Teaching method in university effective classroom teaching mode of use",
Heilongjiang higher education research, vol.2, pp. 32-35, 2012.

[8] Hu Jian-hua, Chen Yu-xiang, Shao Bo, Li Li, Li Xin, Yang Qi-guang, "The reform of higher education in the country 30 years", Education research, vol.17, pp. 11-20, 2008. 